ENCYCLOPEDDIE Encyclopédie berbère

BERBERE

15 | 1995

15 | Daphnitae - Djado

\title{
Didon (Elishat)
}

(voir Carthage)

G. Camps

\section{OpenEdition}

\section{Journals}

Édition électronique

URL : http://journals.openedition.org/encyclopedieberbere/2256

DOI : $10.4000 /$ encyclopedieberbere.2256

ISSN : 2262-7197

\section{Éditeur}

Peeters Publishers

\section{Édition imprimée}

Date de publication : 1 avril 1995

Pagination : 2310-2313

ISBN : 2-85744-808-2

ISSN : 1015-7344

\section{Référence électronique}

G. Camps, « Didon (Elishat) », Encyclopédie berbère [En ligne], 15 | 1995, document D46, mis en ligne le

01 juin 2011, consulté le 10 décembre 2020. URL : http://journals.openedition.org/

encyclopedieberbere/2256 ; DOI : https://doi.org/10.4000/encyclopedieberbere.2256

Ce document a été généré automatiquement le 10 décembre 2020.

(c) Tous droits réservés 


\title{
Didon (Elishat)
}

\author{
(voir Carthage)
}

\section{G. Camps}

1 Didon (Dido, Deido) est le surnom qu'aurait reçu la princesse tyrienne Elishat fondatrice de Carthage d'après une tradition rapportée par de nombreux auteurs de l'Antiquité. Tandis que les Grecs (Timée, Ménandre) restent fidèles à son nom phénicien, qu'ils transforment en Elissa, tout en connaissant son autre nom, les auteurs latins (Ennius, Sevius, Naevius, Justin...) ne la connaissent que sous son nouveau nom de Didon qui fut immortalisé par Virgile.

2 Sur les conditions de la fondation de Carthage* les récits ne manquent pas qui nous comblent de détails, d'autant plus suspects qu'ils sont précis. Le plus circonstancié nous est livré, au II ${ }^{\mathrm{e}}$ siècle après J.-C, par Justin l'abréviateur de l'Histoire romaine de Trogue Pompée ; le plus ancien est un fragment de Denys d'Halicarnasse, résumé de Timée (III ${ }^{\mathrm{e}}$ siècle av. J.-C). Appien, Servius, Eustathe, Naevius, Ovide, Solin, reprennent tour à tour le même récit. Le plus dramatique, le plus romancé aussi, est la triste histoire de Didon que Virgile raconte dans les chants I et IV de l'Enéide. Le point commun à tous ces récits est un assassinat au début, celui du mari d'Elishat, et un suicide de caractère sacrificiel à la fin, celui d'Elishat devenue Didon.

D'après le récit de Justin, Elishat, d'une rare beauté et son jeune frère Pygmalion sont institués co-régents héritiers par Mutho (Metun), roi de Tyr. Mais à la mort de ce dernier, le peuple n'aurait reconnu que Pygmalion, Elishat dépossédée avait épousé son oncle Acherbas (devenu Sychée dans l'Enéide et dont la forme sémitique est Sikarbal), prêtre de Melkart et immensément riche. Dans l'espoir de s'emparer de ces richesses, Pygmalion fait assassiner Acherbas. Apprenant par un songe le nom de l'instigateur du meurtre, Elishat groupe en secret ses partisans et prépare sa fuite. Chargeant les biens d'Acherbas sur des navires, elle trompe Pygmalion en jetant ostensiblement dans le port des sacs remplis de terre, puis invoquant Acherbas, elle le supplie de recevoir, comme offrande funéraire, ces richesses qui avaient causé sa mort. Elle est bientôt rejointe par des notables de Tyr qui se déclarent ses partisans. Les navires des exilés se rendent d'abord à Chypre, comme le veulent les traditions navales des Phéniciens faisant route vers l'extrême occident. Dans l'île, l'aventure d'Elishat change de 
caractère. Jusqu'alors il s'agissait d'un groupe d'exilés, d'un parti, dont le pouvoir royal tyrien avait sans doute accepté, sinon exigé, le départ; mais de nouveaux venus transformèrent totalement ce mouvement. Ce fut d'abord un pacte entre Elishat et le prêtre, sans doute phénicien, d'Ashtart Qunon disent les Latins). Ce personnage et sa famille s'agrégèrent au groupe primitif, firent acte d'allégeance à la princesse tyrienne, en échange le grand prêtre obtint le sacerdoce d'Ashtart dans la nouvelle ville, fonction qui resterait pour toujours un apanage de sa descendance. D'autres personnes, isolément ou par familles entières, vinrent grossir le parti d'Elishat.

4 Sans doute avec l'accord du grand prêtre, si ce n'est même sous son instigation, les Tyriens profitent d'une relève des jeunes filles qui pratiquaient la prostitution sacrée dans le temple d'Ashtart pour les conduire sur leurs navires. Elles étaient au nombre de quatre-vingt. Les navires d'Elishat cinglent alors vers la Libye, suivant une route déjà bien connue des Phéniciens qui avaient fondé sur la côte africaine Utique, Lixus et certainement des comptoirs intermédiaires.

5 Suivant le même récit, les premiers contacts avec les Libyens se firent dans la bonne entente, malgré la tromperie des Tyriens qui, n'ayant obtenu que la cession d'un terrain pouvant être couvert par une peau de bœuf, auraient découpé celle-ci en très fines lanières de façon à délimiter le territoire de ce qui allait devenir la citadelle de Byrsa.

6 Les relations prirent un autre cours avec l'intervention de Hiarbas, roi des Maxitani, qui exigeait d'épouser Didon. Après bien des tergiversations, Didon feignit d'accepter les propositions de Hiarbas, mais soucieuse de rester fidèle à la mémoire de son époux assassiné, elle fit dresser un bûcher destiné à un sacrifice de réparation aux mânes d'Acherbas et, au dernier moment, elle se poignarda et se précipita dans les flammes.

7 Cette belle et troublante légende des origines de Carthage repose sur un certain nombre de données historiques. Les noms des protagonistes, passés cependant par le grec ou le latin, sont connus dans l'onomastique punique: Elishat, que les Grecs appelaient Elissa est un nom bien connu à Carthage, Acherbas (devenu Sichaeus chez Virgile) s'écrivait Sikarbal, Pygmalion est un roi historique de Tyr dont le règne est contemporain des événements rapportés par la légende. Ce roi portait lui aussi un nom théophore ; dans une tombe de Carthage, datant de la fin du viII siècle, a été trouvé un médaillon en or dédié à Astarté et au dieu Pygmalion. Hiarbas est bien un nom libyque, il fut porté par un roi numide du $\mathrm{I}^{\mathrm{er}}$ siècle avant J.-C. Le personnage de la légende est aussi nommé lapon ou lopas, formes dans lesquelles on reconnait facilement le nom de Iobaï dont les Latins firent Juba. Dido (en français Didon) serait un nom africain : on connaît la forme Ded ou Didi qui fut le nom d'un chef libyen qui attaqua l'Egypte au XIII ${ }^{\mathrm{e}}$ siècle avant J.-C.

8 La légende de la peau de bœuf fut sans doute inventée par quelque mythographe grec pour expliquer le nom de la citadelle de Carthage (Barsat, en punique) qui devint, chez les Grecs Byrsa, ce qui veut dire "peau de bœuf ». Enfin J. Desanges a montré que les Maxitani (qu'il faut lire Muxitani) étaient un peuple ou une tribu historique, on retrouve leur nom dans celui d'un pagus de la circonscription de Carthage, à l'époque romaine. Les Muxitani/Maxitani devaient contrôler les collines et plateaux au nord du Bagrada, c'est-à-dire la région même des Afri* qui donnèrent leur nom au pays puis au continent. 
Incarnant la fidélité conjugale au-delà de la mort, Elishat-Didon est une figure héroïque dont le comportement est nullement invraisemblable: elle est la première de ces héroïnes carthaginoises parfaitement historiques qui préférèrent se donner ou accepter la mort plutôt que de survivre aux malheurs de leur patrie. L'holocauste, sacrifice le plus complet chez les Sémites, s'appliquait aux victimes animales mais aussi humaines dont les premières n'étaient, le plus souvent, que le substitut. A Carthage même, le sanctuaire que l'on nomme traditionnellement le tophet, renferme, en une sinistre stratigraphie, la succession des urnes, signalées par des cippes, qui renfermaient les restes calcinés des enfants du premier âge sacrifiés en prémices à Baal Hammon et à la Dame Tanit, face de Baal. Ces sacrifices humains furent pratiqués pendant des siècles ; ils furent progressivement remplacés, sang pour sang, souffle pour souffle, corps pour corps, comme le dit une inscription latine de N'gaous, en Algérie, par des animaux, agneaux ou mêmes colombes ; mais cette horrible pratique n'était pas encore morte aux premiers siècles de notre ère. Le sacrifice de Didon s'inscrit donc dans un contexte psychologique et religieux bien connu.

Sur le plan historique, on conçoit très bien qu'une expédition tyrienne, renforcée de Chypriotes, ait été montée pour rétablir le calme à Tyr, où s'affrontaient peut-être deux partis, l'un favorable au roi Pygmalion, l'autre animé par le personnel du temple de Melqart. Que le parti vaincu ait reçu pour mission de fonder une nouvelle ville en Occident et que pour rendre encore plus officielle cette mission, elle fût confiée à une princesse royale, le fait ne serait nullement invraisemblable. La légende a dramatisé le récit du départ de Didon-Elishat, mais il est sûr qu'il n'y eut aucune rupture, ni de fait, ni de droit, entre Tyr et la Nouvelle Ville, Carthage. Celle-ci, tout au long de son histoire, même lorsqu'elle fut devenue la principale cité du monde phénico-punique, resta fidèle à Tyr et envoya régulièrement sa contribution annuelle au temple de Melqart.

11 Quand se passèrent ces événements? On dispose, dans les différents récits de la fondation de Carthage, de plusieurs traditions qui, dépendant de sources différentes, permettent, selon Timée de la dater 38 ans avant la première Olympiade, soit en 814 avant J.-C, selon Ménandre d'Ephèse, la fondation correspondrait à la septième année du règne de Pygmalion, c'est-à-dire entre 825 et 820 , selon Fabius Pictor, Carthage aurait été fondée 72 ans avant Rome, soit en 820 , mais selon Cicéron, cette différence ne serait que de 65 ans, ce qui donnerait la date de 813 ; enfin selon Velleius Paterculus, Carthage fut détruite 668 ans après sa fondation, ce qui permet de revenir à la date de 814 avant J.-C. Le regroupement est impressionnant, on serait donc tenter d'affirmer que Carthage fut fondée dans le dernier quart $\mathrm{du} \mathrm{IX}^{\mathrm{e}}$ siècle avant $\mathrm{J} . \mathrm{C}$, et plus précisément vers 814. Malheureusement aucun document archéologique n'est encore venu confirmer une date aussi haute. Même la modeste chapelle, découverte par P. Cintas dans le premier niveau d'occupation du tophet ne renfermait pas de céramique antérieure au milieu du viII ${ }^{\mathrm{e}}$ siècle. Les poteries proto-corinthiennes les plus anciennes découvertes dans les tombes de la première nécropole de Carthage datent elles aussi du VIII ${ }^{\mathrm{e}}$ siècle avant J.-C.

12 Cette discordance entre la tradition littéraire et les données archéologiques n'est pas particulière à Carthage. On peut, dans un souci de conciliation, et sans faire appel à d'éventuelles données archéologiques de futures fouilles, penser que la date de «fondation » se rapporte, non pas à la construction de la ville et de sa nécropole, mais 
au moment où aurait été établi un sanctuaire sur ce point de la côte fréquenté sporadiquement, mais non encore véritablement habité.

Quelle que soit l'année où il fut allumé, le bûcher d'Elishat-Didon continua de brûler dans le cœur des Carthaginois tout au long de leur histoire, éclairée par les sinistres feux qui consumaient les corps des enfants sacrifiés à Baal. L'histoire de Carthage commence par le bûcher d'Elishat et se termine par celui dans lequel se jetèrent, en 146 avant J.-C, la femme et les enfants d'Asdrubal, le dernier défenseur de la ville tragique.

INDEX

Mots-clés : Biographie, Mythologie 